\title{
Antifungal Activity of Lipopeptides From Bacillus XT1 CECT 8661 Against Botrytis cinerea
}

\author{
Laura Toral', Miguel Rodríguez ${ }^{2,3}$, Victoria Béjar ${ }^{2,3}$ and Inmaculada Sampedro ${ }^{2,3 *}$ \\ ${ }^{1}$ Xtrem Biotech S.L., European Business Innovation Center, Granada, Spain, ${ }^{2}$ Department of Microbiology, Faculty of \\ Pharmacy, University of Granada, Granada, Spain, ${ }^{3}$ Biomedical Research Center (CIBM), Biotechnology Institute, Granada, \\ Spain
}

This work aims to explore the capacity of a Bacillus methylotrophicus (later heterotypic synonym of Bacillus velezensis) strain named XT1 CECT 8661 against the necrotrophic plant pathogen Botrytis cinerea and to identify the compounds responsible for its activity. Q_TOF electrospray mass spectrometry analysis allows us to detect several lipopeptides - surfactin, bacillomycin, and fengycin - in XT1 cultures. In vitro antibiosis studies demonstrated the efficiency of the lipopeptide fraction for the inhibition of fungal growth. In fact, microscopy studies (SEM/TEM) revealed, an alteration of the

OPEN ACCESS

Edited by:

Jesús Mercado-Blanco, Consejo Superior de Investigaciones

Científicas (CSIC), Spain

Reviewed by:

Massimiliano Morelli, Istituto per la Protezione Sostenibile delle Piante (IPSP), Italy Sotiris Tjamos, Agricultural University of Athens,

Greece

${ }^{*}$ Correspondence: Inmaculada Sampedro isampedro@ugr.es

Specialty section: This article was submitted to Plant Microbe Interactions, a section of the journal

Frontiers in Microbiology

Received: 25 March 2018 Accepted: 30 May 2018 Published: 26 June 2018

Citation:

Toral L, Rodríguez M, Béjar V and Sampedro I (2018) Antifungal Activity of Lipopeptides From Bacillus XT1 CECT 8661 Against Botrytis cinerea.

Front. Microbiol. 9:1315.

doi: 10.3389/fmicb.2018.01315 morphology of the phytopathogen in interaction with lipopeptides, with resistance structures appearing in the early stages of growth of the fungus. Our studies, carried out with tomatoes, grapes, and strawberries have demonstrated the efficiency of Bacillus XT1 CECT 8661 lipopeptides against $B$. cinerea infection and it capability to trigger the antioxidant activity in fruit. Overall, the results of this study highlight the potential of lipopeptides of this strain as an effective biological control agent against the colonisation of $B$. cinerea.

Keywords: Bacillus XT1, lipopeptides, antifungal activity, Botrytis cinerea, antioxidant activity

\section{INTRODUCTION}

Botrytis cinerea [teleomorph: Botryotinia fuckeliana (de Bary) Whetzel] is a necrotrophic fungi known to be the cause of grey mould. These fungi can infect more than 200 plant species, including horticulturally important crops (Gao et al., 2018). Therefore, it has significant economic relevance, causing huge economic losses (Dean et al., 2012). The ability to produce conidiophores that contain conidia gives it the ability to remain quiescent until conditions are favourable enough to produce the infection (Gao et al., 2018). The production of lytic enzymes along with other phytotoxic metabolites induces cell death in plant tissues, mainly affecting those in a state of senescence or with wounds on their surface (Finiti et al., 2014; Gonzalez-Fernandez et al., 2015; Yu et al., 2015; Yahaya et al., 2016). The aforementioned ubiquity, together with the capacity to produce resistant structures and the high mutation rate of $B$. cinerea, makes the fight against this fungus a challenging task (Gonzalez-Fernandez et al., 2015; Haidar et al., 2016).

Currently, the most popular treatment to combat grey mould is the extensive use of pesticides; however, recent regulations of these products have considerably restricted the possibility of their use. These pesticides produce residual waste and contaminate ground water increasing the risks for human health and the environment (Perez-Garcia et al., 2011; Romanazzi et al., 2012; Finiti et al., 2014). As a consequence, one of the biggest challenges for sustainable agriculture 
is the development of environmentally friendly alternatives such as the use of microorganisms. The biological control through bacterial strains has been an objective of particular interest due to their multiple modes of action against different plant diseases. One of these mechanisms is the production of a wide variety of biologically active compounds with great potential for biotechnological applications (Gond et al., 2015; MartinezHidalgo et al., 2015; Mnif et al., 2016).

Although several microorganisms have been described as potential candidates for biological control agents, numerous research studies have focused on members of the genus Bacillus. Species from this genus have been considered biologically safe and are commonly used in agriculture. The sporulation capacity of these microorganisms gives them a high resistance, high ubiquity in diverse habitats and stability in formulated products (Ongena and Jacques, 2008; Tanaka et al., 2015; Mnif et al., 2016). Members of the genus Bacillus are well known for their capacity to colonise roots, promote plant growth (PGPR) and induce systemic resistance mechanism in plants (Sicuia et al., 2015). In addition, they can produce a broad spectrum of biologically active molecules, with potential antimicrobial and antifungal properties. One of the major factors related with the antifungal activity of members of the genus Bacillus is due to the production of lipopeptides (Ongena and Jacques, 2008).

Lipopeptides are low-molecular-weight cyclic amphiphilic oligopeptides synthesised by multi-enzyme complexes called non-ribosomal peptide synthetases (NRPSs) (Romero et al., 2007; Gond et al., 2015; Han et al., 2015; Deng et al., 2017). Species from the genus Bacillus produce molecules which are mainly classified into three families depending on their amino-acid sequence: surfactin, iturin, and fengycin. These families share a cyclic $\beta$-amino or $\beta$-hydroxy fatty acid linked to a lipid tail (Tapi et al., 2010; Sumi et al., 2014; Jemil et al., 2017). Biological activities may differ from one compound to another depending on the type of amino-acid residues, the cyclisation of the peptide and the length and branching of the fatty acid chain (Ongena and Jacques, 2008; Frikha-Gargouri et al., 2017).

Different studies have demonstrated the activity of lipopeptides produced by Bacillus subtilis (Farace et al., 2015; Wang et al., 2015; Arroyave-Toro et al., 2017). However, the information about the antifungal activity of lipopeptides produced by $B$. methylotrophicus against $B$. cinerea is almost non-existent.

The objective of this study is to analyse the antifungal activity of B. methylotrophicus XT1 CECT 8661 (later reclassified as heterotypic synonym B. velezensis) (Ruiz-García et al., 2005) against $B$. cinerea. For this purpose, the lipopeptides produced by $B$. methylothrophicus by this strain were identified, the genes involved in their biosynthesis were detected and their antifungal activity was tested in vitro. Alterations of the morphology of the phytopathogen in interaction with these macromolecules was examined via microscopy studies. Furthermore, studies of antibiosis in vivo and determination of antioxidant compounds on grapes, tomatoes, and strawberries were carried out in order to demonstrate the ability of these compounds to protect against $B$. cinerea infection and to activate antioxidant mechanisms. To the best of our knowledge, this is the first report that describes the ability of lipopeptides to trigger the antioxidant activity in fruit, a mechanism involved in the elicitation of an induced systemic resistance phenomenon.

\section{MATERIALS AND METHODS}

\section{Bacterial and Fungal Strains}

The bacterial strain used in this study was the patented strain Bacillus XT1 CECT 8661, licenced to Xtrem Biotech S.L., which was isolated from a rhizospheric soil sample in the south of Spain (Béjar et al., 2014). The strain was originally classified as B. methylotrophicus and it was later reclassified as a heterotypic synonym of $B$. velezensis. It was routinely cultivated on a nutrient broth and nutrient agar at $28^{\circ} \mathrm{C}$. The phytopathogenic fungus B. cinerea was kindly provided by the University of Zaragoza (Spain) and was maintained on potato dextrose agar (PDA) and potato dextrose broth (PDB) and incubated at $24^{\circ} \mathrm{C}$.

\section{Antifungal Activity of XT1 Strain}

The antifungal activity of XT1 strain against $B$. cinerea was determined in both solid and liquid mediums. For the solid assay strain XT1 was spread on a $1 \mathrm{~cm}^{2}$ area on one side of a PDA agar plate (at $1 \mathrm{~cm}$ from the plate wall) and an $8-\mathrm{mm}$-agar disc of the mycelium of fungi was deposited on the opposite side. The maximum and minimum values of the fungal mycelium radius obtained were measured after a 15-day incubation period at $25^{\circ} \mathrm{C}$. The results were expressed as a percentage of the mycelium inhibition rate $(\mathrm{IR} \%=\mathrm{A}-\mathrm{B} / \mathrm{A} \times 100)$ where $A$ was the maximum value of the mycelium radius and $B$ was the minimum value. For the antifungal assay in liquid medium, first, the time in which the antifungal activity was the maximum was determinate cultivating the strain XT1 in MOLP (medium optimal for lipopeptide production) (Ahimou et al., 2000) at different times (24, 48, 72, and $96 \mathrm{~h}$ ), then the supernatant was tested against $B$. cinerea following the procedure described below. A 15-day culture of $B$. cinerea in PDB was crushed in a breaker and filtered with gauze, all under sterile conditions. The spore concentration was adjusted to $5 \times 10^{7}$ conidia $\mathrm{mL}^{-1}$ and penicillin $\mathrm{G}\left(2.5 \mathrm{mg} \mathrm{mL}^{-1}\right)$ and streptomicin $\left(10 \mathrm{mg} \mathrm{mL}^{-1}\right)$ was added to the spore suspension. The experiment was carried out on multiwell culture plates (Cellstar*) with 48 wells where $900 \mu \mathrm{l}$ of the spore solution was subjected to $300 \mu \mathrm{L}$ of different times XT1 supernatant, obtained after centrifugation of the XT1 culture in MOLP at $10000 \mathrm{rpm} 20 \mathrm{~min}$. Inoculated medium with cycloheximide $50 \mu \mathrm{g}$ $\mathrm{mL}^{-1}$ was used as a positive control for growth inhibition, whilst PDB inoculated with spore suspension without treatment was considered as the negative control. The plates were incubated at $25^{\circ} \mathrm{C}$ for 7 days. The results were obtained by observing the presence or absence of fungal growth (Frikha-Gargouri et al., 2017).

\section{Lipopeptide Production}

Three different liquid media have been tested for lipopeptide production: MOLP medium (Ahimou et al., 2000); SG medium (Schaeffer et al., 1965; Leighton and Doi, 1971), and a commercial 
concentrated beef medium (CM) (ox concentrate $43 \%$ and yeast extract 24\%). Lipopeptides were extracted according to Yazgan et al. (2001) with slight modifications. Briefly, the culture supernatant of strain XT1 was subjected to an organic extraction with one volume $n$-butanol three times using a decantation funnel. Then, the organic phase was evaporated with a vacuum concentrator.

\section{Antifungal Activity of the Lipopeptides Produced by XT1}

Lipopeptide antifungal activity was tested by preparing $20 \mathrm{~mL}$ of lipopeptide solution at different concentrations: $20,10,8,6,4$, 2,1 , and $0.5 \mathrm{mg} \mathrm{mL}^{-1}$ (w/v in distilled water) in $50 \mathrm{~mL}$ tubes. Then $0.8 \mathrm{~g}$ PDA was added to each lipopeptide solution; the negative control was made with untreated PDA medium. The tubes were then sterilised and the medium were poured into $90 \mathrm{~mm}$ Petri plates. Next, a fungal plug of 15 days of mycelial growing $B$. cinerea was deposited in the middle of each plate and maintained at $25^{\circ} \mathrm{C}$ for 15 days. After that, the mycelial growth inhibition percentage was calculated after 15 day's incubation by the comparison between the diameter of mycelial growing in the control plates and the treatments according to the following formula: mycelial growth inhibition $=100-[$ (diameter of control mycelium diameter of mycelium in lipopeptide medium /diameter of control mycelium) $\times 100$ ] (Borah et al., 2016).

\section{Determination of Minimal Inhibitory Concentration (MIC) and Minimal Fungicidal Concentration (MFC) of the Lipopeptides}

The minimal inhibitory concentration (MIC), defined as the smallest concentration of lipopetides that inhibits the fungal growth totally and the minimal fungicidal concentration (MFC), defined as the lowest concentration of lipopeptides capable of killing the fungi, was determined. The experiment was carried out in liquid medium according to the protocol described previously in the "Antifungal Activity of XT1 Strain" section. However, in this case $900 \mu \mathrm{l}$ of the spore solution was exposed to $300 \mu \mathrm{L}$ of lipopeptide dilutions $20,10,8,6,4,2,1$, and $0.5 \mathrm{mg} \mathrm{mL}^{-1}$. The plates were incubated at $25^{\circ} \mathrm{C}$ for 7 days. The results were obtained by observing the presence or absence of fungal growth. The whole content from each well, where there was no growth of $B$. cinerea, was passed to tubes with PDB medium and incubated at $25^{\circ} \mathrm{C}$ for 7 days for the determination of MFC (Frikha-Gargouri et al., 2017).

\section{Stability of Lipopeptides to Heat and pH}

The antifungal activity of a lipopeptide solution $\left(10 \mathrm{mg} \mathrm{mL}^{-1}\right)$ from XT1 was determined after 10,30, and $60 \mathrm{~min}$ of heating at $100^{\circ} \mathrm{C}$ and after $20 \mathrm{~min}$ at $121^{\circ} \mathrm{C}$. The stability was also determined at different $\mathrm{pH}$ in the range comprised between 3 to 12 (Ghribi et al., 2012). The antifungal activity was tested in liquid medium according to the method described above (FrikhaGargouri et al., 2017).

\section{Genetic Characterization of Lipopeptides}

Genes encoding NRPS production were amplified by polymerase reaction chain (PCR) from genomic DNA of the XT1 strain. PCR was carried out using the specific and degenerated primers described in Table 1. PCR amplifications were achieved in $50 \mu \mathrm{L}$ mixtures with PCR buffer, $2 \mathrm{mM} \mathrm{MgCl}_{2}, 4 \mathrm{mM}$ of each primer, $5 \mathrm{U}$ Taq polymerase, $0.2 \mathrm{mM}$ of each dNTP, and 80-100 ng of genomic DNA. The amplification conditions were: $95^{\circ} \mathrm{C}$ for $5 \mathrm{~min}, 40$ cycles of $94^{\circ} \mathrm{C}$ for $1 \mathrm{~min}$, annealing temperature for $1 \mathrm{~min}, 72^{\circ} \mathrm{C}$ extension for $1 \mathrm{~min}$; and a final extension at $72^{\circ} \mathrm{C}$ for $10 \mathrm{~min}$. The annealing temperatures were 45 , 43, 50, 53, and $50^{\circ} \mathrm{C}$ for, Af2/Tf1, As1/Ts2, BmyBF/BmyBR, ItuDF/ItuDR, and SrfA3/LicA3 primers, respectively. The amplification products were analysed by electrophoresis in a $2 \%$ $(\mathrm{w} / \mathrm{v})$ agarose gel.

\section{Identification of Lipopeptides Using UPLC - HDMS Q-TOF}

The residue obtained from lipopeptide extraccion was dissolved in $10 \%$ methanol and analysed by high-pressure liquid chromatography (UPLC) (Acquity UPLC ${ }^{\circledR}$ BEH300, Waters) coupled to a high definition mass spectrometry (SYNAPT G2 HDMS Q-TOF. Waters). Mass spectrometry was carried out by positive ionisation electrospray (ESI+). The obtained data were processed by the MassLynx ${ }^{\mathrm{TM}}$ software (Waters).

TABLE 1 | PCR primers of lipopeptides biosynthesis genes in Bacillus XT1.

\begin{tabular}{|c|c|c|c|c|c|}
\hline Lipopeptide & Gene & Primers & Primer sequences $\left(5^{\prime} \rightarrow 3^{\prime}\right)$ & PCR product size (bp) & Reference \\
\hline Surfactin/Lichenicin & & SifA3/licA3 (R) & AGCGGCAYATATTGATGCGGYTC & & \\
\hline & & Tf1 (R) & GCTTWWADKGAATSBCCGCC & & \\
\hline \multirow[t]{2}{*}{ Surfactin } & sifA-A & As1 (F) & CGCGGMTACCGVATYGAGC & $419-431$ & Tapi et al., 2010 \\
\hline & & Ts2 (R) & ATBCCTITBTWDGAATGTCCGCC & & \\
\hline Bacillomycin & & BmyB (R) & GCGGGTATTGAATGCTTGTT & & \\
\hline \multirow[t]{2}{*}{ Iturin } & $i t u D$ & $\operatorname{ltuD}(\mathrm{F})$ & TTGAAYGTCAGYGCSCCTIT & 482 & Chung et al., 2008 \\
\hline & & ItuD (R) & TGCGMAAATAATGGSGTCGT & & \\
\hline
\end{tabular}




\section{Scanning Electron Microscopy and Transmission Electron Microscope of Mycelia Treated With Lipopeptides}

Solid culture medium plates with the negative control treatments and lipopeptides $10 \mathrm{mg} \cdot \mathrm{mL}^{-1}$ from the previously experiment described in the "Antifungal Activity of the Lipopeptides Produced by XT1" section, were used to observe the morphology of $B$. cinerea. The samples were fixed and observed in a FIB-FESEM (CrossBeam NVision $40^{\circledR}$, Carl Zeiss SMT) Scanning Electron Microscope and Transmission Electron Microscope.

\section{Bioassay Against B. cinerea in Grapes, Strawberries, and Tomatoes}

Antifungal activity of lipopeptides produced by XT1 was tested on grapes, strawberries, and tomatoes. B. cinerea was grown for 15 days on a PDA medium at $25^{\circ} \mathrm{C}$ and conidia were collected with sterile distilled water and filtered through four layers of sterile cheesecloth. The surface of the fruit was sterilised with 5\% $\mathrm{NaOCl}$ for $5 \mathrm{~min}$ and rinsed three times with plenty of sterile water. Wounds of $3 \mathrm{~mm}$ were performed with a sterile scalpel on the surface of the grapes, then $15 \mu \mathrm{l}$ of a $20 \mathrm{mg} \cdot \mathrm{mL}^{-1}$ solutions of lipopeptides were applied on the injury. One hour later, when the fruit was dried at room temperature, $15 \mu \mathrm{L}$ of a suspension of $B$. cinerea $10^{8}$ conidia $\mathrm{mL}^{-1}$ were inoculated into the wound. Strawberries and tomatoes were cut into slices and treated by spray with the same lipopeptide solution as in the previous case. Then, after $1 \mathrm{~h}$, the fruit was infected by spraying with the conidia suspension of $B$. cinerea. All the treatments were incubated at $25^{\circ} \mathrm{C}, 70 \%$ humidity for 6 days. For each treatment, a total of nine fruits were used and three technical replicates were performed. Effect was measured and expressed as disease incidence (\% of infected fruit).

\section{Antioxidant Activity on Fruit Treated With Lipopeptides}

The antioxidant activity was measured extracting the soluble phenols and by FRAP assay (ferric iron reducing antioxidant power assay). Total soluble phenols were extracted from $0.1 \mathrm{~g}$ of lyophilized fruits with $10 \mathrm{~mL}$ of $80 \%$ methanol and $0.1 \%$ hydrochloric acid. The mixture was placed in the dark at $4{ }^{\circ} \mathrm{C}$ for $2 \mathrm{~h}$. The supernatant was filtered and the extract was used for the determination of the phenol content and the FRAP assay. The amount of total phenols was determined according to the Folin-Ciocalteu's procedure described by Ribereau-Gayon (1968) with slight modifications. The phenol content was estimated from a standard curve of gallic acid (GAE) and the results expressed as $\mathrm{mg}$ of gallic acid $100 \mathrm{~g}^{-1} \mathrm{~d} . \mathrm{w}$ (dry weight). In FRAP assay an extract of fruit $(0.2 \mathrm{~mL})$ (prepared as for phenol determination) was added to $2 \mathrm{~mL}$ of FRAP solution [0.25 mol $\mathrm{L}^{-1}$ acetate buffer ( $\mathrm{pH} 3.6$ ) containing $1 \mathrm{mmol} \mathrm{L}^{-1}$ 2,4,6-tris(2pyridyl)-s-triazine (TPTZ) and $\left.20 \mathrm{mmol} \mathrm{L}^{-1} \mathrm{FeCl}_{3} \cdot 6 \mathrm{H}_{2} \mathrm{O}\right]$ and incubated $5 \mathrm{~min}$ at room temperature measuring the absorbance at $593 \mathrm{~nm}$. A standard of $1 \mathrm{mmol} \mathrm{L}^{-1} \mathrm{~L}$-ascorbic acid in distilled water was prepared. Results were expressed as mmol

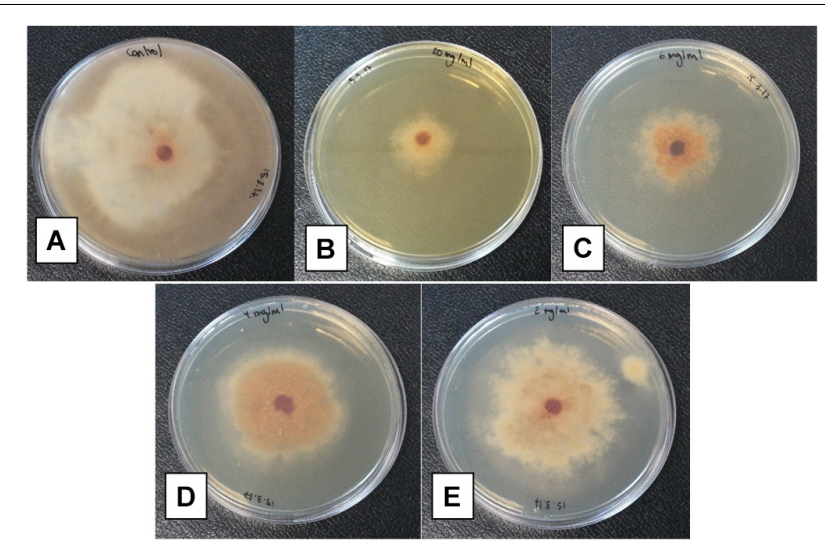

FIGURE 1 | Antifungal activity of Bacillus XT1 lipopeptides toward Botrytis cinerea. Effect of different concentrations on the antifungal potency: negative control (A) and in the presence of: $10 \mathrm{mg} \mathrm{mL}^{-1}$ lipopeptide (B), $6 \mathrm{mg} \mathrm{mL}^{-1}$ lipopeptide (C), $4 \mathrm{mg} \mathrm{mL}^{-1}$ lipopeptide (D), and $2 \mathrm{mg} \mathrm{mL}^{-1}$ lipopeptide (E).

$\mathrm{L}^{-1}$ of $\mathrm{Fe}^{2+}$ equivalents $100 \mathrm{~g}^{-1}$ dry weight (Benzie and Strain, 1999).

\section{Statistical Analyses}

Data obtained were subjected to ANOVA and multiple pair-wise comparisons were performed by the Duncan's multiple range test.

\section{RESULTS}

\section{Antifungal Activity of Bacillus XT1}

Antifungal production in the supernatant was detected after $24 \mathrm{~h}$ of aerobic culture and reached its maximum at $72 \mathrm{~h}$. The XT1 strain showed antifungal activity against $B$. cinerea in both solid and liquid media (inhibition rates of 60 and $100 \%$, respectively).

\section{Lipopeptide Production}

The production of lipopeptides was tested in different culture media. The data showed that MOLP medium increased the lipopeptide production compared with other media. The best production yield was obtained with this medium $\left(10 \mathrm{~g} \mathrm{~L}^{-1}\right)$; however, the production with other media such as SG and the commercial medium (CM) decreased the production of lipopeptide to 2.8 and $2.13 \mathrm{~g} \mathrm{~L}^{-1}$, respectively.

\section{Antifungal Activity of the Lipopeptides Produced by Bacillus XT1}

The antifungal activity of Bacillus XT1 lipopeptides toward $B$. cinerea was also analysed. The results demonstrated that lipopeptides produced by XT1 inhibit the growth of $B$. cinerea. Inhibition rates of $72,48,30$, and $19 \%$ of the mycelium diameter were observed for the concentrations of lipopeptides of $10,6,4$, and $2 \mathrm{mg} \mathrm{mL}{ }^{-1}$, respectively, after 15 days of treatment (Figure 1). In general, lipopeptides from XT1 showed antagonistic activity against $B$. cinerea across a broad spectrum of concentrations in a dose response manner (Figure 1). 


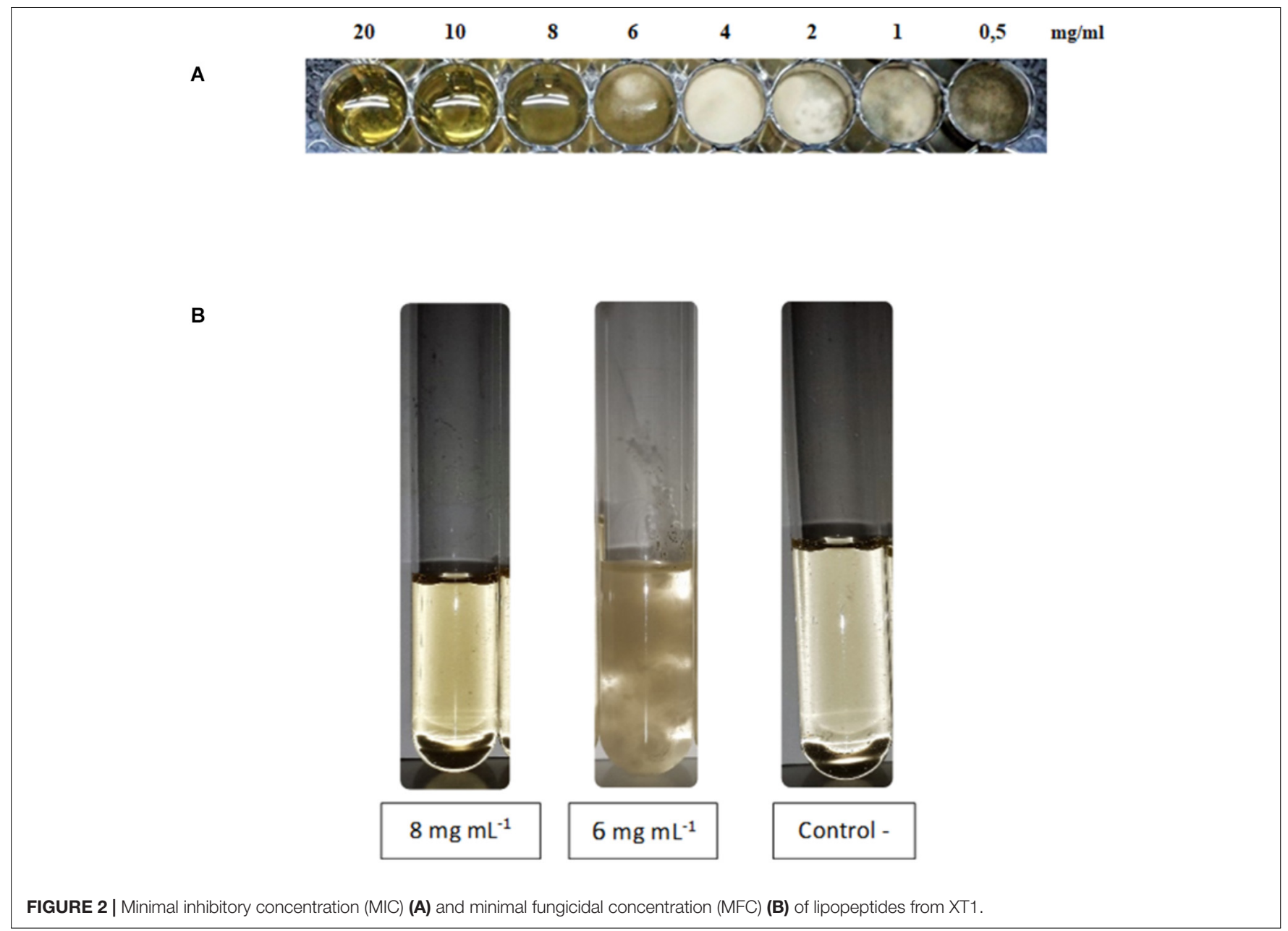

\section{Determination of Minimal Inhibitory Concentration (MIC) and Minimal Fungicidal Concentration (MFC) of the Lipopeptides}

Lipopeptides from XT1 were also tested in multiwell culture plates with 48 wells to test the MIC and in culture tubes to test the MFC. As shown in Figure 2A lipopeptides concentrations tested ranging from 20 to $0.5 \mathrm{mg} \mathrm{mL}^{-1}$ and a significant inhibitory effect of lipopeptides was observed at concentrations as low as $8 \mathrm{mg} \mathrm{mL}^{-1}$ which corresponds to the MIC. The MFC was also $8 \mathrm{mg} \mathrm{mL}^{-1}$ (Figure 2B).

\section{Stability of Lipopeptides to Heat and pH}

The antifungal potency was not affected by any heat treatment. However, the antifungal potency of lipopeptides from XT1 was affected at $\mathrm{pH} 3$ and $\mathrm{pH} 12$. The optimum range of $\mathrm{pH}$ for the maximum antifungal efficacy was between 7 and 9 .

\section{Detection of Genes Involved in Lipopeptide Biosynthesis}

Genomic analysis of Bacillus XT1 indicates that it contains gene clusters for non-ribosomal lipopeptide synthetases. Amplicons of the expected sizes were obtained for fengycin, surfactin, bacillomycin, and iturin genes $s r f \mathrm{~A}-\mathrm{C}, f e n \mathrm{C}, \operatorname{srf} \mathrm{A}-\mathrm{A}, b m y \mathrm{~B}$, and ituD.

\section{Identification of Lipopeptides Using UPLC - HDMS Q-TOF}

Electrospray quadrupole time-of-flight mass spectrometry (QTOF MS) analyses were carried out in this study to identify the metabolites produced by XT1. Figure 3 illustrates the total ion chromatogram (TIC) spectrum of the lipopeptide extract from a XT1 culture supernatant.

These analyses showed that the strain XT1 produces several forms of different lipopeptides. Four known surfactins with an acyl chain ranging from $\mathrm{C} 12$ to $\mathrm{C} 15$ were detected, whereas three known bacillomycins D (C14, C15, and C16) were also detected. Two peaks corresponding to the fengycin A and fengycin B were also observed (Table 2). There were no mass signals for iturin.

Quadrupole time-of-flight mass spectrometry analysis indicated five types of lipopeptides and two predominant compounds. This analysis detected a $[\mathrm{M}+\mathrm{H}]$ peak at $\mathrm{m} / \mathrm{z}$ 1022.6729 and afforded the molecular formula $\mathrm{C}_{52} \mathrm{H}_{91} \mathrm{~N}_{7} \mathrm{O}_{13}$ (i-Fit $=20.6$ and DBE $=10.5)$ and corresponding to surfactin and $[\mathrm{M}+\mathrm{H}]$ peak at $\mathrm{m} / \mathrm{z} 1463.8038$ corresponding to fengycin 


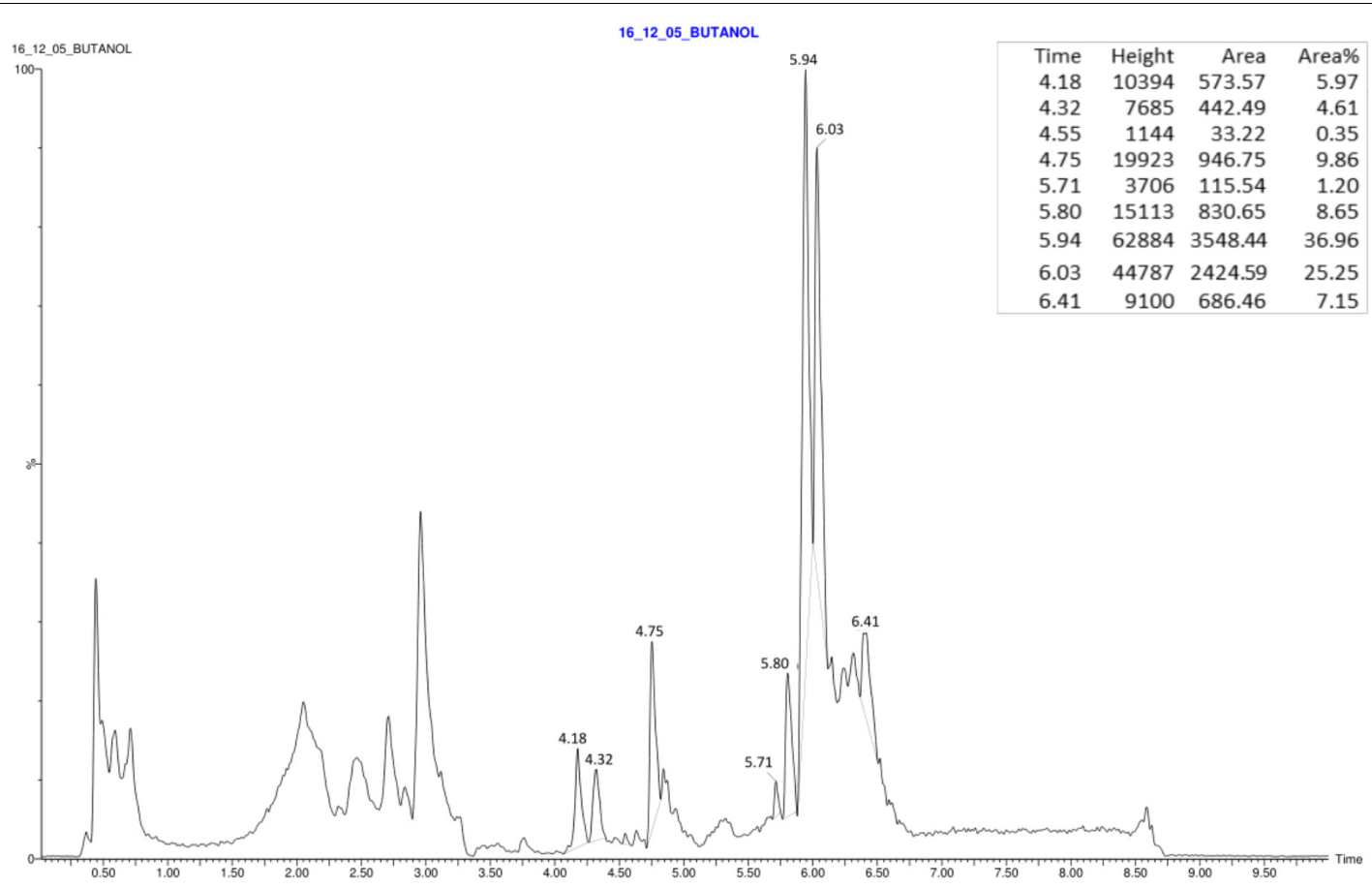

FIGURE 3 | Total ion chromatogram (TIC) spectrum obtained from the surfactant of Bacillus XT1.

A with the molecular formula $\mathrm{C}_{72} \mathrm{H}_{110} \mathrm{~N}_{12} \mathrm{O}_{20}$ (i-Fit $=30.2$ and $\mathrm{DBE}=23.5$ ) (Figures $4 \mathrm{C}$ and $\mathbf{4 A}$, respectively).

Quadrupole time-of-flight mass spectrometry analysis indicated five types of lipopeptides and two predominant compounds. This analysis detected a $[\mathrm{M}+\mathrm{H}]$ peak at $\mathrm{m} / \mathrm{z} 1031.5431$ (1053.5276 corresponds to the complementary sodium adduct molecular ion $[\mathrm{M}+\mathrm{Na}]$ ) with the molecular formula $\mathrm{C}_{48} \mathrm{H}_{75} \mathrm{~N}_{10} \mathrm{O}_{15}$ (i-Fit $=101.1$ and $\mathrm{DBE}=16.5$ ) corresponding to bacillomycin $\mathrm{D}$, a $[\mathrm{M}+\mathrm{H}]$ peak at $\mathrm{m} / \mathrm{z}$ 1463.8038 with the molecular formula $\mathrm{C}_{72} \mathrm{H}_{110} \mathrm{~N}_{12} \mathrm{O}_{20}$ (i-Fit $=130.3$ and $\mathrm{DBE}=23.5)$ corresponding to fengycin $\mathrm{A}$ and a $[\mathrm{M}+\mathrm{H}]$ peak at $\mathrm{m} / \mathrm{z} 1022.6729$ and afforded the molecular formula $\mathrm{C}_{52} \mathrm{H}_{91} \mathrm{~N}_{7} \mathrm{O}_{13}(\mathrm{i}-$ Fit $=161.5$ and $\mathrm{DBE}=10.5)$ and corresponding to surfactin (Figures 4A, 4B, and 4C, respectively).

\section{Effect of XT1 Lipopeptides on B. cinerea Mycelial Growth}

Microscopy data of $B$. cinerea mycelial growth treated with XT1 lipopeptides are shown in Figure 5. Scanning electron microscopy (SEM) analyses of $B$. cinerea mycelium treated with the MIC/MFC of lipopeptides $\left(8 \mathrm{mg} \mathrm{mL}^{-1}\right)$ from XT1 showed important alterations of pathogen morphology. Hyphae treated without lipopeptides grew normally with straight appearance and their surfaces were smooth (Figure 5A). However, after exposure to lipopeptides, one of the most striking features was the appearance of structures of resistance (Figure 5B).

Transmission electron microscopy (TEM) images of normal hyphae treated without lipopeptides showed smooth surfaces, intact cells, well defined enclosing cell walls and the cellular

TABLE 2 | Lipopeptide production by Bacillus XT1 as detected by Q-TOF MS.

\begin{tabular}{|c|c|c|c|c|c|}
\hline Lipopeptide & Fatty chain length & {$[\mathrm{M}+\mathrm{H}]^{+}$} & Retention time (min) & Area (\%) & Peak intensity \\
\hline & C15 & 1045.5585 & 4.32 & 4.61 & $8.35 \mathrm{e} 3$ \\
\hline Fengycin A & C16 & 1463.8038 & 4.75 & 9.86 & $4.81 \mathrm{e} 3$ \\
\hline \multirow[t]{2}{*}{ Fengycin B } & $\mathrm{C} 15$ & 1477.8329 & 4.86 & 0.60 & $1.65 \mathrm{e} 3$ \\
\hline & C16 & 1491.8481 & 4.86 & 0.60 & $1.01 \mathrm{e} 3$ \\
\hline & $\mathrm{C} 13$ & 1008.6564 & 5.80 & 8.65 & $1.06 \mathrm{e} 4$ \\
\hline & C14 & 1022.6729 & 5.94 & 36.96 & $8.40 \mathrm{e} 4$ \\
\hline & C15 & 1036.6867 & 6.03 & 25.25 & $6.60 \mathrm{e} 4$ \\
\hline
\end{tabular}




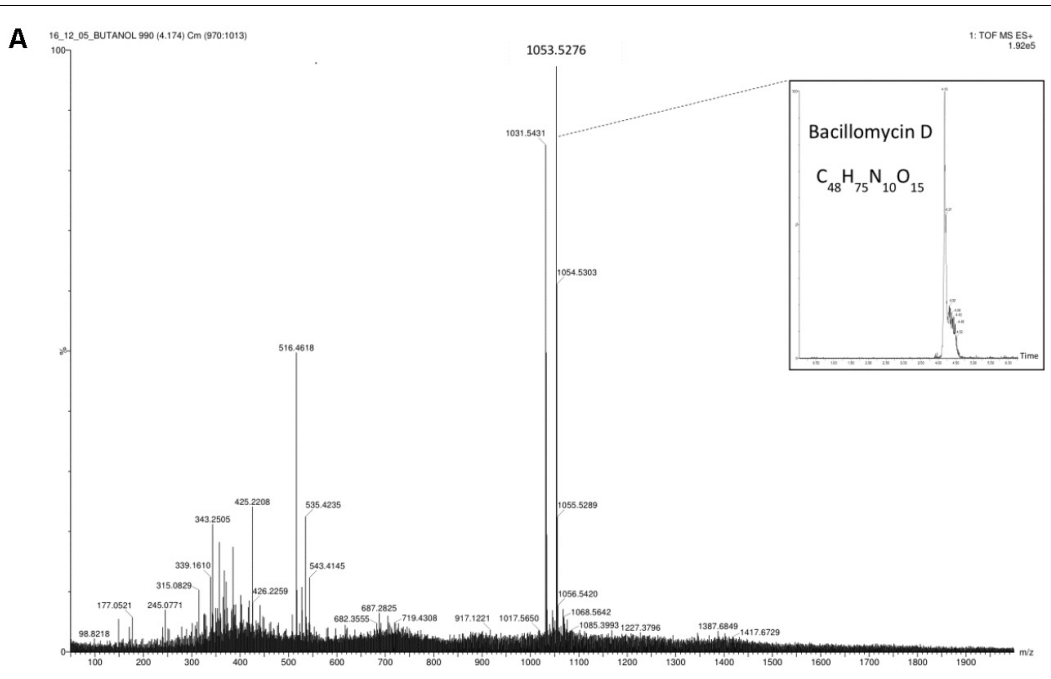

B

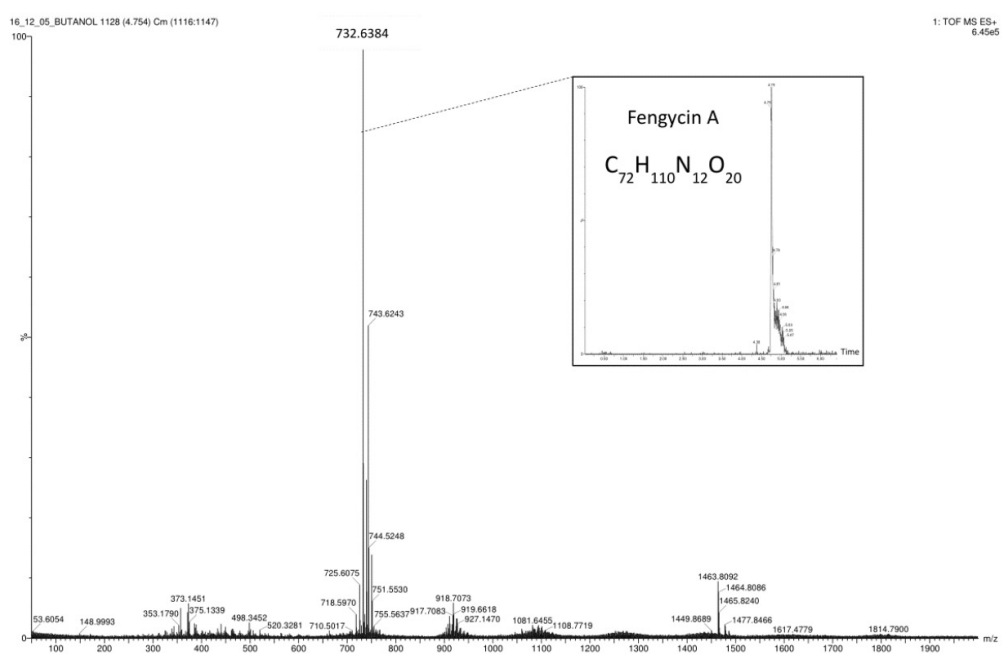

C

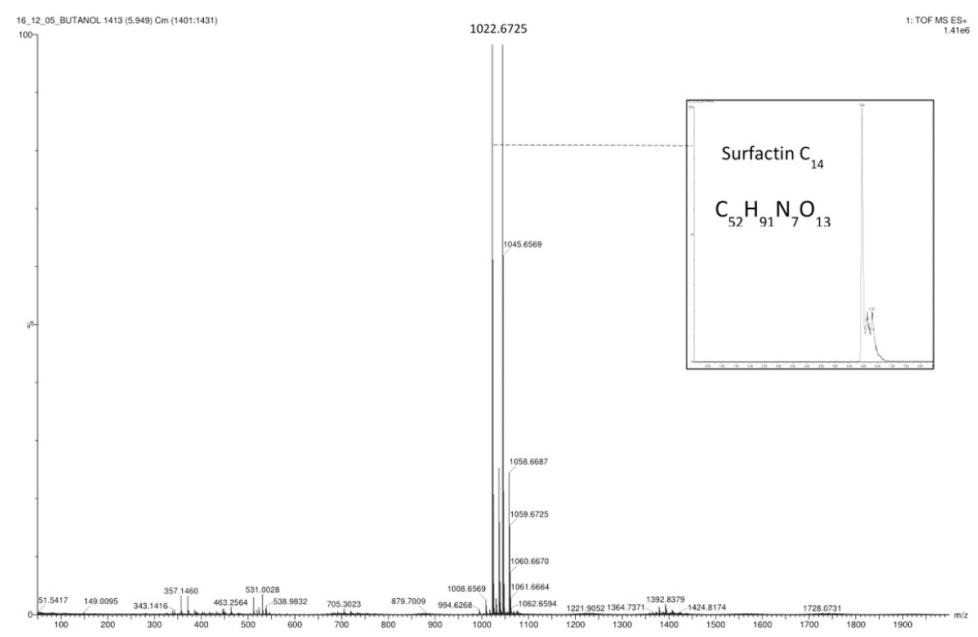

FIGURE 4 | Quadrupole time-of-flight mass spectrometry (Q-TOF MS) spectra obtained from the surfactant produced by Bacillus XT1: protonated linear derivatives of the $[\mathrm{M}+\mathrm{H}]$ of bacillomycin $\mathrm{D}(\mathbf{A})$, fengycin $\mathbf{A}(\mathbf{B})$, and surfactin $(\mathbf{C})$. 


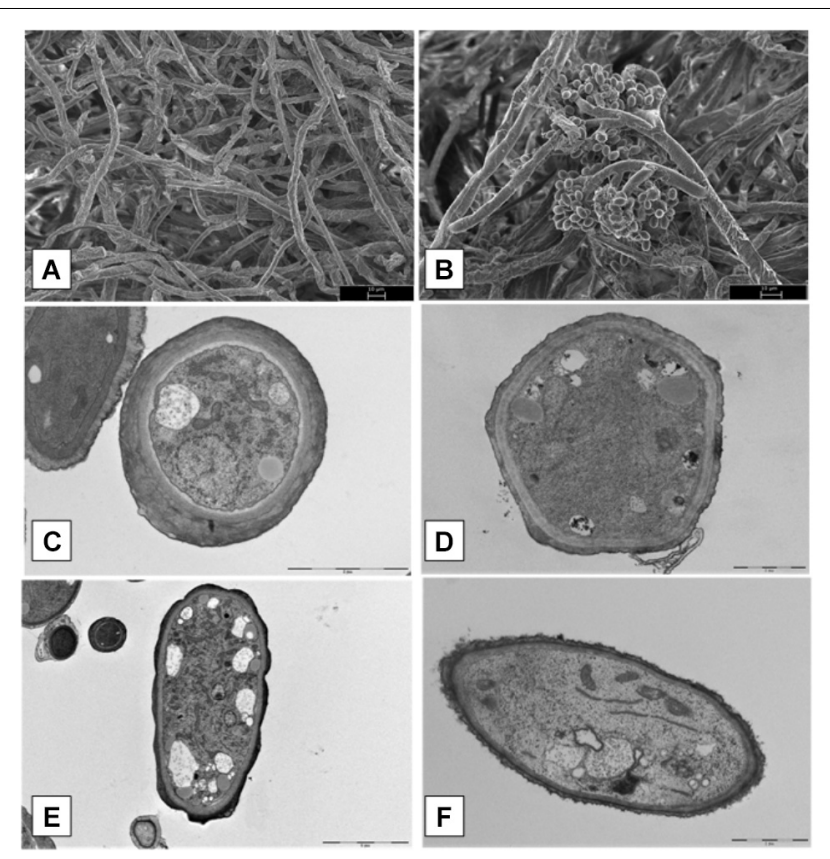

FIGURE 5 | Scanning electron microscopy (SEM) and transmission electron microscopy (TEM) micrographs of hyphae of Botrytis cinerea treated with lipopeptides. Hyphae treated without and with lipopeptides (SEM) (A,B, respectively). Hyphae treated without and with lipopeptides (TEM) (C,E and D,F, respectively).

organelles in normal arrangements (Figures 5C,E). TEM images of hyphae confirmed that in the treatment of $B$. cinerea with lipopeptide organelles were degenerated and gathered in clumps (Figures 5D,F).

\section{Bioassay Against B. cinerea in Grapes, Strawberries, and Tomatoes}

The MIC/MFC of lipopeptide extract from XT1 $\left(8 \mathrm{mg} \mathrm{mL}^{-1}\right)$ was applied in order to evaluate the protector effect with different fruit infected with $B$. cinerea. The lipopeptides were injected in grapes and sprayed onto strawberries and tomatoes. The level of disease infections decreased in all the fruit treated with XT1 lipopeptides.

The disease incidence in grapes, strawberries, and tomatoes treated with $B$. cinerea was 71,100 , and $100 \%$, respectively. The disease reductions in fruit treated with XT1 lipopeptides were 100, 12, and 50\%, respectively (Table 3 and Figures 6, 7). The results show that antifungal lipopeptide treated fruit reduced the disease symptoms significantly compared to non-treated fruits except in strawberries where the effect was not so evident. This reduction is higher for grapes.

\section{Antioxidant Activity on Fruit Treated With Lipopeptides}

The antioxidant activity was tested in grapes where the highest disease reduction was observed. The antioxidant activity of grape extracts, as estimated by the FRAP assay increased significantly with the inoculation of the MIC/MFC of lipopeptides produced by XT1 (Figure 8A). Although an increase in the antioxidant activity was also observed in grapes infected with the pathogen, the highest increases were observed in the treatment with the lipopeptides.

On the other hand, total phenol content also increased with the exposure of fruit to the lipopeptides but the increase is only significant in the uninfected grapes. In this case the increase of total phenol content is of $30 \%$ (Figure 8B).

\section{DISCUSSION}

The strain Bacillus XT1 is a gram positive, sporulated, and halotolerant rod that grows in a wide range of salt concentrations $(0-12 \% \mathrm{w} / \mathrm{v})$, temperature $\left(15-40^{\circ} \mathrm{C}\right)$, and $\mathrm{pH}(5-10)$ (Béjar et al., 2014). The strain was originally classified as B. methylotrophicus XT1 CECT 8661 (deposited according to the Bucharest Treaty for patenting purposes and licenced to Xtrem Biotech S.L.). The species $B$. methylotrophicus was later reclassified as a heterotypic synonym of $B$. velezensis (Dunlap et al., 2016).

This paper describes the antifungal activity of the strain and its lipopeptides against $B$. cinerea, a filamentous fungus classified as the second most important phytopathogen worldwide. Also demonstrate the implication of XT1 lipopeptides in the in vivo antibiosis and in the alteration of fungus structures and in the induced systemic response of fruits affected with the fungi.

One of the major factors related with the antifungal activity of members of the genus Bacillus is due to the production of lipopeptides synthesised by NRPSs such as iturin, fengycin, and surfactin (Romero et al., 2007; Ongena and Jacques, 2008; Pramudito et al., 2018). Lipopeptides are produced as a mixture of macromolecules belonging to the same family or class. Genomic analysis of Bacillus XT1 indicated that it contains gene clusters for non-ribosomal lipopeptide synthetases related to the production of surfactin, iturin, fengycin, and bacillomycin. Detection of the

TABLE 3 | Disease incidence in grapes, strawberries, and tomatoes.

Disease incidence (\%)

\begin{tabular}{|c|c|c|c|c|}
\hline & Control & XT1 lipopeptides & Botrytis & XT1 lipopeptides + Botrytis \\
\hline Grapes & $0 \pm 0.00 a$ & $0 \pm 0.00 a$ & $71 \pm 0.18 b$ & $0 \pm 0.00 a$ \\
\hline Strawberry & $43 \pm 0.25 b$ & $33 \pm 0.00 a$ & $100 \pm 0.00 d$ & $88 \pm 0.58 c$ \\
\hline Tomato & $25 \pm 0.20 b$ & $0 \pm 0.17 a$ & $100 \pm 0.00 d$ & $50 \pm 0.13 c$ \\
\hline
\end{tabular}

Values followed by the same letters for each fruit did not differ significantly according to Duncan's multiple range test ( $p<0.05)$. 

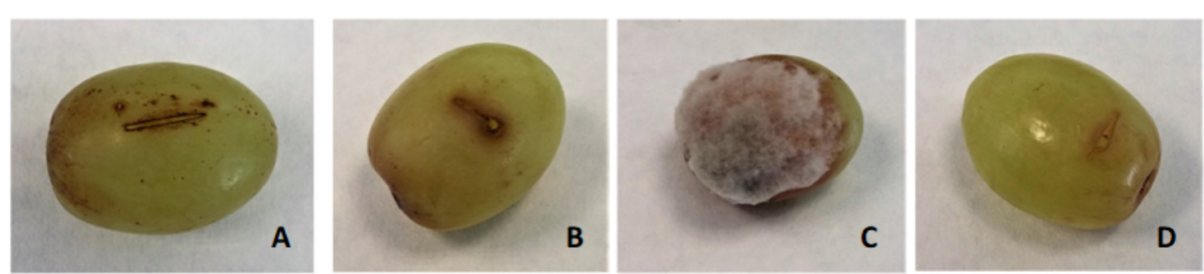

FIGURE 6 | Lipopeptides from XT1 inhibited disease severity in grapes. Disease severity of grey mould on grapes. (A) Grapes treated with sterile water as the negative control. (B) Grapes treated with lipopeptides from XT1. (C) Grapes infected with Botrytis cinerea. (D) Grapes infected with B. cinerea and treated with lipopeptides from XT1.

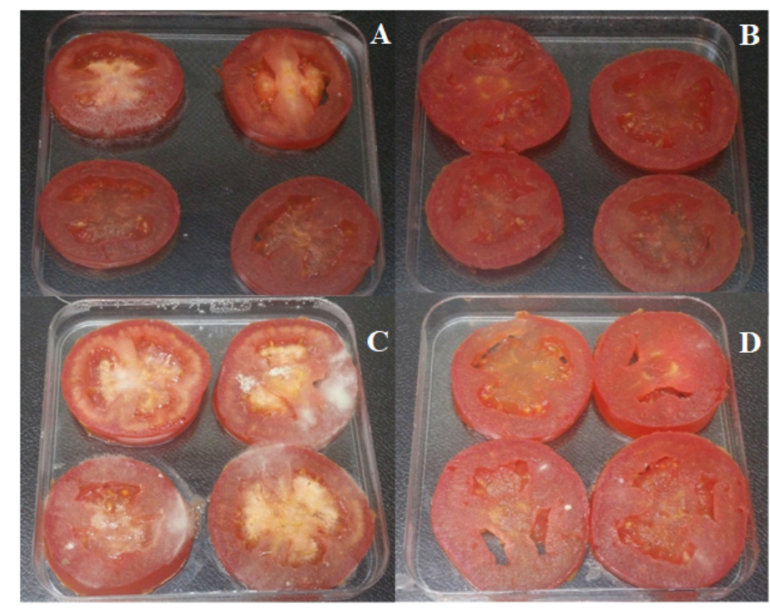

FIGURE 7 | Lipopeptides from XT1 inhibited disease severity in tomatoes. Disease severity of grey mould on tomatoes. (A) Tomatoes treated with sterile water as the negative control. (B) Tomatoes treated with lipopeptides from XT1. (C) Tomatoes infected with Botrytis cinerea. (D) Tomatoes infected with B. cinerea and treated with lipopeptides from XT1.

produced lipopeptides by XT1 was performed by Q-TOF MS analysis showing that strain XT1 produces all lipopeptides except iturin. Some of these macromolecules were previously shown to be produced by other B. methylotrophicus strains (FrikhaGargouri et al., 2017).

Lipopeptides biosynthesis from XT1 was tested in different culture media. The data showed that the culture medium used in the growth of the microorganism could decisively influence the production of lipopeptides. Ahimou et al. (2000) described an optimum medium (named MOLP medium) for lipopeptide production by Bacillus subtilis. This study concluded that the medium MOLP is also the best to increase the lipopeptide production yields in B. methylotrophicus by Bacillus XT1. The influence of culture conditions on lipopeptide production was previously described for other strains of Bacillus genus like B. subtilis or B. amyloliquefaciens (Monteiro et al., 2005; Medeot et al., 2017). In terms of stability, the thermostable nature of XT1 lipopeptides and the fact that these antifungal compounds were affected by extremely alkaline $\mathrm{pH}$ were also observed in the evaluation of the activity of the B. subtilis biosurfactant (Ghribi et al., 2012).

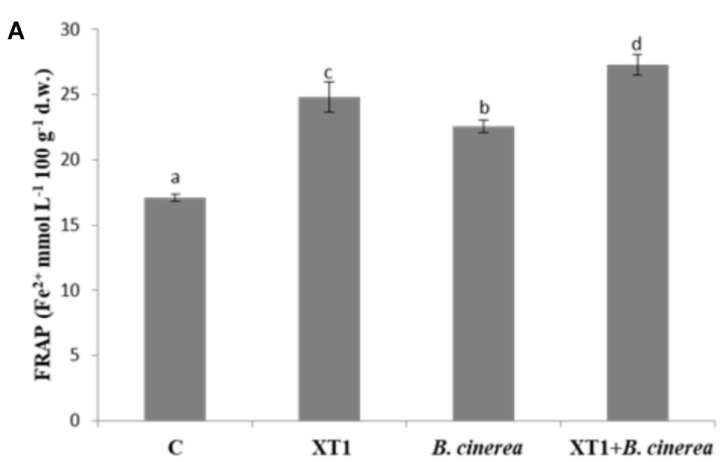

B

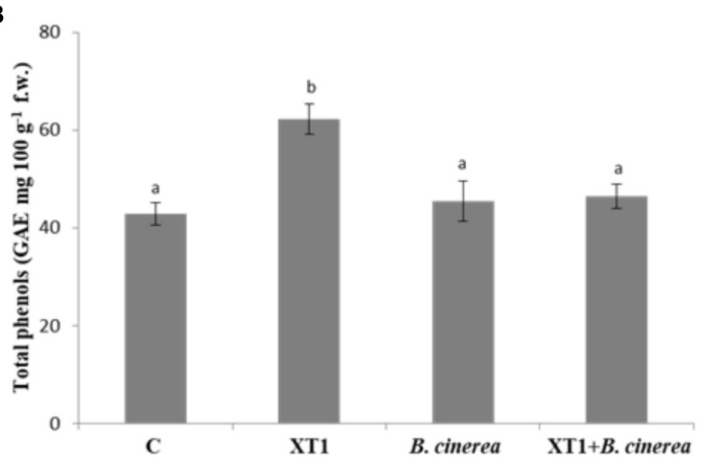

FIGURE 8 | Antioxidant activity evaluated with the FRAP assay (A) and total phenols $(\mathbf{B})$ of grapes treated with lipopeptides from XT1, infected with Botrytis cinerea and infected with $B$. cinerea but treated with lipopeptides from XT1. Values followed by the same letters did not differ significantly according to Duncan's multiple range test $(p<0.05)$. Vertical lines represent the standard errors of the mean.

Several studies have previously highlighted the antagonistic effect against different pathogens of NRP metabolites such as lipopeptides (Chowdhury et al., 2015; Mnif and Ghribi, 2015). For example, it has been demonstrated that the biocontrol of Bacillus strains against different pathogenic bacteria and fungi such as Aspergillus or Pseudomonas syringae is facilitated by lipopeptides such as surfactin (Bais et al., 2004). According to the literature, few studies describe the inhibitory activity of the lipopeptides produced by Bacillus strains against $B$. cinerea. All the studies reported the antibiosis of $B$. cinerea by the NRPs metabolites produced by $B$. subtilis but do not demonstrate directly the implications of these molecules in the antibiosis 
(Tareq et al., 2014; Farace et al., 2015; Wang et al., 2015; ArroyaveToro et al., 2017). The same occurs with B. amyloliquefaciens (Ji et al., 2013; Pretorius et al., 2015; Tanaka et al., 2015; Zhang et al., 2017), B. marinus (Gu et al., 2017), B. atrophaeus (Zhang et al., 2013), and B. velezensis (Ge et al., 2016; Romero et al., 2016; Gao et al., 2017).

With respect to the activity of lipopeptides, Romano et al. (2013) reported the non-effect of $B$. amyloliquefaciens lipopeptides against $B$. cinerea at concentrations of $0.1 \mathrm{mg} \mathrm{mL}^{-1}$. Tareq et al. (2014) established a range of lipopeptide activity in B. subtilis between 0.5 to $300 \mu \mathrm{g} \mathrm{mL}^{-1}$ and Zhang et al. (2017) determined the maximum activity of lipopeptides of B. amyloliquefaciens at $30 \mathrm{mg} \mathrm{mL} \mathrm{m}^{-1}$. Our study tested a range of concentrations from 0.5 to $20 \mathrm{mg} \mathrm{mL}^{-1}$ and confirmed the antifungal activity of XT1 lipopeptides with inhibitory and fungicidal effects of these compounds at concentrations as low as $8 \mathrm{mg} \mathrm{mL}^{-1}$ (MIC and MFC). This fact and the higher productions of lipopeptides in MOLP medium may determine the high fungicidal activity of Bacillus XT1 against $B$. cinerea.

Different studies show that lipopeptides from Bacillus sp. strains produce damage to the hyphae and survival structures of pathogenic fungi (Souto et al., 2004). Chitarra et al. (2003) suggested that lipopeptides produced by B. subtilis YM 10-20 may permeabilize fungal spores and inhibit their germination. Other studies show the swelling and the deformation of fungus hyphae of Pestalotiopsis eugeniae when treated by the lipopeptides of B. subtilis BS-99-H (Lin et al., 2010). The effects of the lipopeptides produced by XT1 on the morphology of $B$. cinerea were evaluated in solid media. SEM studies revealed an extensive formation of fungal spores in the intersection of the fungusbacteria inhibition zone. The same results were observed in previous studies where the biological activity of lipopeptides from B. amyloliquefaciens against Fusarium solani was analysed (Torres et al., 2017). Gong et al. (2014) studied the effect of bacillomycin D from B. subtilis on Aspergillus flavus and concluded that due to the amphipathic nature of bacillomycin $\mathrm{D}$, this compound entered the spores and the hyphae where it caused pores to be formed in the membrane, resulting in the leakage of cell contents. TEM images of hyphae confirmed that in the treatment of $B$. cinerea with XT1 lipopeptides the organelles degenerated probably due to the entry of these compounds.

In this study, the antifungal activity of lipopeptides from XT1 against grey mould disease in different fruit was also investigated. The inoculation results showed that grey mould disease on grapes and tomatoes was significantly inhibited by the lipopeptides produced by XT1. Previous studies have described the involvement of lipopeptides from $B$. subtilis in grapevine plant defence and local resistance against $B$. cinerea (Farace et al., 2015). They also showed that lipopeptides are perceived by grapevine plant cells and activate different signalling pathways.

\section{REFERENCES}

Ahimou, F., Jacques, P., and Deleu, M. (2000). Surfactin and iturin A effects on Bacillus subtilis surface hydrophobicity. Enzyme Microb. Tech. 27, 749-754. doi: 10.1016/S0141-0229(00)0 0295-7
Previous studies suggest that lipopeptides act as elicitors of defence-related genes (Waewthongrak et al., 2014). However, and to the best of our knowledge, our study is the first to highlight the ability of lipopeptides to trigger the antioxidant activity of these macromolecules in fruit. The total phenol content was increased significantly with the exposure of the fruit to the lipopeptides produced by XT1. The highest increases in antioxidant activity were observed in the infected fruits and in those treated with the lipopeptides. These data may suggest that the antimicrobial effect of lipopeptides and the accumulation of antioxidant compounds are closely related with pathogen resistance.

\section{CONCLUSION}

In this study, we have investigated the high antifungal activity against B. cinerea of a patented strain, Bacillus XT1 CECT 8661. The lipopeptides produced by XT1 are involved in the biological control of $B$. cinerea and trigger the antioxidant activity in fruit. Based on the inhibitory effect on the development of grey mould on grapes and tomatoes, Bacillus XT1 CECT 8661 could be considered as a potential alternative for chemical fungicides in reducing the damage of grey mould disease.

\section{AUTHOR CONTRIBUTIONS}

LT carried out the experimental techniques and statistical analysis. MR collaborated in the experimental techniques related with determination of lipopeptide genes and analysis of the chromatograms. VB collaborated in the design of the techniques related with the extraction and the study of antifungal activity of lipopeptides, analysed the results, and critically read the manuscript. IS designed the experimental techniques, analysed the results, and drafted the manuscript.

\section{FUNDING}

This study was supported by the European Project for Industrial Doctorates "H2020" (UGR-Ref. 4726), by the Ramón y Cajal Project (RYC-2014-15532) from MINECO and the Project RetosColaboración from MINECO (2015, RTC-2015-4121-2).

\section{ACKNOWLEDGMENTS}

IS wishes to thank MINECO for her "Ramón y Cajal" contract. The authors thank Angela Tate and Javier Velasco for correcting the English revision of this manuscript.

Arroyave-Toro, J. J., Mosquera, S., and Villegas-Escobar, V. (2017). Biocontrol activity of Bacillus subtilis EA-CB0015 cells and lipopeptides against postharvest fungal pathogens. Biol. Control. 114, 195-200. doi: 10.1016/j.biocontrol.2017. 08.014

Bais, H. P., Fall, R., and Vivanco, J. M. (2004). Biocontrol of Bacillus subtilis against infection of Arabidopsis roots by Pseudomonas syringae is facilitated 
by biofilm formation and surfactin production. Plant Physiol. 134, 307-319. doi: 10.1104/pp.103.028712

Béjar, V., Llamas, I., Ruíz-García, C., and Quesada, E. (2014). Uso de Bacillus methylotrophicus como estimulante del crecimiento vegetal y medio de control biológico, y cepas aisladas de dicha especie. EP. Patent No 3178325A1, U.S. Patent No 20170215429. Granada: University of Granada, Xtrem Biotech SL.

Benzie, I. F. F., and Strain, J. J. (1999). Ferric reducing/antioxidant power assay: direct measure of total antioxidant activity of biological fluids and modified version for simultaneous measurement of total antioxidant power and ascorbic acid concentration. Methods Enzymol 299, 15-27. doi: 10.1016/S0076-6879(99) 99005-5

Borah, S. N., Goswami, D., Sarma, H. K., Cameotra, S. S., and Deka, S. (2016). Rhamnolipid biosurfactant against Fusarium verticillioides to control stalk and ear rot disease of maize. Front. Microbiol. 7:1505. doi: 10.3389/fmicb.2016.0 1505

Chitarra, G., Breeuwer, P., Nout, M., Van Aelst, A., Rombouts, F., and Abee, T. (2003). An antifungal compound produced by Bacillus subtilis YM 10-20 inhibits germination of Penicillium roqueforti conidiospores. J. Appl. Microbiol. 94, 159-166. doi: 10.1046/j.1365-2672.2003.01819.x

Chowdhury, S. P., Hartmann, A., Gao, X., and Borriss, R. (2015). Biocontrol mechanism by root-associated Bacillus amyloliquefaciens FZB42, a review. Front. Microbiol. 6:780. doi: 10.3389/fmicb.2015.00780

Chung, S., Kong, H., Buyer, J. S., Lakshman, D. K., Lydon, J., Kim, S. D., et al. (2008). Isolation and partial characterization of Bacillus subtilis ME488 for suppression of soilborne pathogens of cucumber and pepper. Appl. Microbiol. Biotechnol. 80, 115-123. doi: 10.1007/s00253-008-1520-4

Dean, R., Van Kan, J. A., Pretorius, Z. A., Hammond-Kosack, K. E., Di Pietro, A., Spanu, P. D., et al. (2012). The top 10 fungal pathogens in molecular plant pathology. Mol. Plant. Pathol. 13, 414-430. doi: 10.1111/j.1364-3703.2011. 00783.x

Deng, Q., Wang, W., Sun, L., Wang, Y., Liao, J., Xu, D., et al. (2017). A sensitive method for simultaneous quantitative determination of surfactin and iturin by LC-MS/MS. Anal. Bioanal.Chem. 409, 179-191. doi: 10.1007/s00216-0169984-z

Dunlap C., Kim S. J., Kwon S. W., Rooney A. (2016). Bacillus velezensis is not a later heterotypic synonym of Bacillus amyloliquefaciens; Bacillus methylotrophicus, Bacillus amyloliquefaciens subsp. plantarum and 'Bacillus oryzicola' are later heterotypic synonyms of of Bacillus velezensis based on phylogenomics. Int. J. Syst. Evol. Microbiol. 66, 1212-1217. doi: 10.1099/ijsem.0.000858

Farace, G., Fernandez, O., Jacquens, L., Coutte, F., Krier, F., Jacques, P., et al. (2015). Cyclic lipopeptides from Bacillus subtilis activate distinct patterns of defence responses in grapevine. Mol. Plant. Pathol. 16, 177-187. doi: 10.1111/ mpp. 12170

Finiti, I., de la O Leyva, M., Vicedo, B., Gomez-Pastor, R., Lopez-Cruz, J., GarciaAgustin, P., et al. (2014). Hexanoic acid protects tomato plants against Botrytis cinerea by priming defence responses and reducing oxidative stress. Mol. Plant. Pathol. 15, 550-562. doi: 10.1111/mpp.12112

Frikha-Gargouri, O., Ben Abdallah, D., Ghorbel, I., Charfeddine, I., Jlaiel, L., Triki, M. A., et al. (2017). Lipopeptides from a novel Bacillus methylotrophicus 39b strain suppress Agrobacterium crown gall tumours on tomato plants. Pest. Manag. Sci. 73, 568-574. doi: 10.1002/ps.4331

Gao, P., Qin, J., Li, D., and Zhou, S. (2018). Inhibitory effect and possible mechanism of a Pseudomonas strain QBA5 against gray mold on tomato leaves and fruits caused by Botrytis cinerea. PLoS. One. 13:e0190932. doi: 10.1371/ journal.pone.0190932

Gao, Z., Zhang, B., Liu, H., Han, J., and Zhang, Y. (2017). Identification of endophytic Bacillus velezensis ZSY-1 strain and antifungal activity of its volatile compounds against Alternaria solani and Botrytis cinerea. Biol. Control. 105, 27-39. doi: 10.1016/j.biocontrol.2016.11.007

Ge, B., Liu, B., Nwet, T. T., Zhao, W., Shi, L., and Zhang, K. (2016). Bacillus methylotrophicus strain NKG-1, isolated from Changbai Mountain, China, has potential applications as a biofertilizer or biocontrol agent. PLoS. One. 11:e0166079. doi: 10.1371/journal.pone.0166079

Ghribi, D., Elleuch, M., Abdelkefi, L., and Ellouze-Chaabouni, S. (2012). Evaluation of larvicidal potency of Bacillus subtilis SPB1 biosurfactant against Ephestia kuehniella (Lepidoptera: Pyralidae) larvae and influence of abiotic factors on its insecticidal activity. J. Stored Prod. Res. 48, 68-72. doi: 10.1016/j.jspr.2011. 10.002
Gond, S. K., Bergen, M. S., Torres, M. S., and White, J. F. Jr. (2015). Endophytic Bacillus spp. produce antifungal lipopeptides and induce host defence gene expression in maize. Microbiol. Res. 172, 79-87. doi: 10.1016/j.micres.2014. 11.004

Gong, Q., Zhang, C., Lu, F., Zhao, H., Bie, X., and Lu, Z. (2014). Identification of bacillomycin D from Bacillus subtilis fmbJ and its inhibition effects against Aspergillus flavus. Food Control. 36, 8-14. doi: 10.1016/j.foodcont.2013.07.034

Gonzalez-Fernandez, R., Valero-Galvan, J., Gomez-Galvez, F. J., and Jorrin-Novo, J. V. (2015). Unraveling the in vitro secretome of the phytopathogen Botrytis cinerea to understand the interaction with its hosts. Front. Plant. Sci. 6:839. doi: $10.3389 /$ fpls.2015.00839

Gu, K. M., Zhang, D. J., Guan, C., Xu, J. H., Li, S. L., Shen, G. M., et al. (2017). Safe antifungal lipopeptides derived from Bacillus marinus B-9987 against grey mold caused by Botrytis cinerea. J. Integr. Agr. 16, 1999-2008. doi: 10.1016/s20953119(16)61616-7

Haidar, R., Fermaud, M., Calvo-Garrido, C., Roudet, J., and Deschamps, A. (2016). Modes of action for biological control of Botrytis cinerea by antagonistic bacteria. Phytopathol. Mediterr. 55, 301-322. doi: 10.14601/Phytopathol_ Mediterr-18079

Han, Q., Wu, F., Wang, X., Qi, H., Shi, L., Ren, A., et al. (2015). The bacterial lipopeptide iturins induce Verticillium dahliae cell death by affecting fungal signalling pathways and mediate plant defence responses involved in pathogenassociated molecular pattern-triggered immunity. Environ. microbiol. 17, 11661188. doi: $10.1111 / 1462-2920.12538$

Jemil, N., Manresa, A., Rabanal, F., Ben Ayed, H., Hmidet, N., and Nasri, M. (2017). Structural characterization and identification of cyclic lipopeptides produced by Bacillus methylotrophicus DCS1 strain. J. Chromatogr. B. Analyt. Technol. Biomed. Life. Sci. 1060, 374-386. doi: 10.1016/j.jchromb.2017. 06.013

Ji, S. H., Paul, N. C., Deng, J. X., Kim, Y. S., Yun, B. S., and Yu, S. H. (2013). Biocontrol activity of Bacillus amyloliquefaciens CNU114001 against fungal plant diseases. Mycobiology 41, 234-242. doi: 10.5941/MYCO.2013.41.4.234

Leighton, T. J., and Doi, R. H. (1971). The stability of messenger ribonucleic acid during sporulation in Bacillus subtilis. J. Biol. Chem. 246, 3189-3195.

Lin, H. F., Chen, T. H., and Liu, S. D. (2010). Bioactivity of antifungal substance iturin A produced by Bacillus subtilis strain BS-99-H against Pestalotiopsis eugeniae, a causal pathogen of wax apple fruit rot. Plant Pathol. Bull. 19, 225-233.

Martinez-Hidalgo, P., Garcia, J. M., and Pozo, M. J. (2015). Induced systemic resistance against Botrytis cinerea by Micromonospora strains isolated from root nodules. Front. Microbiol. 6:922. doi: 10.3389/fmicb.2015.00922

Medeot, D. B., Bertorello-Cuenca, M., Liaudat, J. P., Alvarez, F., Flores-Cáceres, M. L., and Jofré, E. (2017). Improvement of biomass and cyclic lipopeptides production in Bacillus amyloliquefaciens MEP 218 by modifying carbon and nitrogen sources and ratios of the culture media. Biol. Control. 115, 119-128. doi: 10.1016/j.biocontrol.2017.10.002

Mnif, I., and Ghribi, D. (2015). Potential of bacterial derived biopesticides in pest management. Crop. Prot. 77, 52-64. doi: 10.1016/j.cropro.2015.07.017

Mnif, I., Grau-Campistany, A., Coronel-Leon, J., Hammami, I., Triki, M. A., Manresa, A., et al. (2016). Purification and identification of Bacillus subtilis SPB1 lipopeptide biosurfactant exhibiting antifungal activity against Rhizoctonia bataticola and Rhizoctonia solani. Environ. Sci. Pollut. Res. Int. 23, 6690-6699. doi: 10.1007/s11356-015-5826-3

Monteiro, L., Mariano, R. D. L. R., and Souto-Maior, A. M. (2005). Antagonism of Bacillus spp. against Xanthomonas campestris pv. campestris. Braz. Arch. Biol. Tech. 48, 23-29. doi: 10.1590/S1516-89132005000100004

Mora, I., Cabrefiga, J., and Montesinos, E. (2011). Antimicrobial peptide genes in Bacillus strains from plant environments. Int. Microbiol. 14, 213-223. doi: $10.2436 / 20.1501 .01 .151$

Ongena, M., and Jacques, P. (2008). Bacillus lipopeptides: versatile weapons for plant disease biocontrol. Trends. Microbiol. 16, 115-125. doi: 10.1016/j.tim. 2007.12.009

Perez-Garcia, A., Romero, D., and de Vicente, A. (2011). Plant protection and growth stimulation by microorganisms: biotechnological applications of Bacilli in agriculture. Curr. Opin. Biotechnol. 22, 187-193. doi: 10.1016/j.copbio.2010. 12.003

Pramudito, T. E., Agustina, D., Nguyen, T. K. N., and Suwanto, A. (2018). A novel variant of narrow-spectrum antifungal bacterial lipopeptides that strongly 
inhibit Ganoderma boninense. Probiotics. Antimicrob. Proteins. 10, 110-117. doi: 10.1007/s12602-017-9334-2

Pretorius, D., van Rooyen, J., and Clarke, K. G. (2015). Enhanced production of antifungal lipopeptides by Bacillus amyloliquefaciens for biocontrol of postharvest disease. N. Biotechnol. 32, 243-252. doi: 10.1016/j.nbt.2014.12.003

Randall Simpson, D., Ravi Natraj, N., McInerney, M., and Duncan, K. (2011). Biosurfactant-producing Bacillus are present in produced brines from Oklahoma oil reservoirs with a wide range of salinities. Appl. Microbiol. Biotechnol. 91, 1083-1093. doi: 10.1007/s00253-011-3326-z

Ribereau-Gayon, P. R. (1968). Les Composés phénoliques des végétaux. Malakoff Cedex, Dunod.

Romanazzi, G., Lichter, A., Gabler, F. M., and Smilanick, J. L. (2012). Recent advances on the use of natural and safe alternatives to conventional methods to control postharvest gray mold of table grapes. Postharvest. Biol. Tech. 63, 141-147. doi: 10.1016/j.postharvbio.2011.06.013

Romano, A., Vitullo, D., Senatore, M., Lima, G., and Lanzotti, V. (2013). Antifungal cyclic lipopeptides from Bacillus amyloliquefaciens strain BO5A. J. Nat. Prod. 76, 2019-2025. doi: 10.1021/np400119n

Romero, D., de Vicente, A., Olmos, J. L., Davila, J. C., and Perez-Garcia, A. (2007). Effect of lipopeptides of antagonistic strains of Bacillus subtilis on the morphology and ultrastructure of the cucurbit fungal pathogen Podosphaera fusca. J. Appl. Microbiol. 103, 969-976. doi: 10.1111/j.1365-2672.2007.03323.x

Romero, F. M., Marina, M., and Pieckenstain, F. L. (2016). Novel components of leaf bacterial communities of field-grown tomato plants and their potential for plant growth promotion and biocontrol of tomato diseases. Res. Microbiol. 167, 222-233. doi: 10.1016/j.resmic.2015.11.001

Ruiz-García C., Béjar V., Martínez-Checa F., Llamas I., Quesada E. (2005). Bacillus velezensis sp. nov., a surfactant-producing bacterium isolated from the river Vélez in Málaga, southern Spain. Int. J. Syst. Evol. Microbiol. 55, 191-195. doi: 10.1099/ijs.0.63310-0

Schaeffer, P., Millet, J., and Aubert, J. P. (1965). Catabolic repression of bacterial sporulation. Proc. Natl. Acad. Sci. U.S.A. 54, 704-711. doi: 10.1073/pnas.54. 3.704

Sicuia, O. A., Constantinescu, F., and Cornea, C. P. (2015). Biodiversity of Bacillus subtilis group and beneficial traits of Bacillus species useful in plant protection. Rom. Biotech. Lett. 20, 10737-10750.

Souto, G. I., Correa, O. S., Montecchia, M. S., Kerber, N. L., Pucheu, N. L., Bachur, M., et al. (2004). Genetic and functional characterization of a Bacillus sp. strain excreting surfactin and antifungal metabolites partially identified as iturin-like compounds. J. Appl. Microbiol. 97, 1247-1256. doi: 10.1111/j.13652672.2004.02408.x

Sumi, C. D., Yang, B. W., Yeo, I.-C., and Hahm, Y. T. (2014). Antimicrobial peptides of the genus Bacillus: a new era for antibiotics. Can. J. Microbiol. 61, 93-103. doi: 10.1139/cjm-2014-0613

Tanaka, K., Amaki, Y., Ishihara, A., and Nakajima, H. (2015). Synergistic effects of [Ile(7)]Surfactin homologues with Bacillomycin D in suppression of gray mold disease by Bacillus amyloliquefaciens biocontrol strain SD-32. J. Agric. Food. Chem. 63, 5344-5353. doi: 10.1021/acs.jafc.5b01198

Tapi, A., Chollet-Imbert, M., Scherens, B., and Jacques, P. (2010). New approach for the detection of non-ribosomal peptide synthetase genes in Bacillus strains by polymerase chain reaction. Appl. Microbiol. Biotechnol. 85, 1521-1531. doi: 10.1007/s00253-009-2176-4

Tareq, F. S., Lee, M. A., Lee, H. S., Lee, Y. J., Lee, J. S., Hasan, C. M., et al. (2014). Non-cytotoxic antifungal agents: isolation and structures of gageopeptides A-D from a Bacillus strain 109GGC020. J. Agric. Food. Chem. 62, 5565-5572. doi: 10.1021/jf502436r

Torres, M. J., Pérez Brandan, C., Sabaté, D. C., Petroselli, G., Erra-Balsells, R., and Audisio, M. C. (2017). Biological activity of the lipopeptide-producing Bacillus amyloliquefaciens PGPBacCA1 on common bean Phaseolus vulgaris L. pathogens. Biol. Control. 105, 93-99. doi: 10.1016/j.biocontrol.2016.1 2.001

Waewthongrak, W., Leelasuphakul, W., and McCollum, G. (2014). Cyclic lipopeptides from Bacillus subtilis ABS-S14 elicit defense-related gene expression in citrus fruit. PLoS. One. 9:e109386. doi: 10.1371/journal.pone. 0109386

Wang, T., Liang, Y., Wu, M., Chen, Z., Lin, J., and Yang, L. (2015). Natural products from Bacillus subtilis with antimicrobial properties. Chinese J. Chem. Eng. 23, 744-754. doi: 10.1016/j.cjche.2014.05.020

Yahaya, S., Fagwalawa, L., Ali, M., Abdullahi, H., Umma, M., Lawan, M., et al. (2016). Symptomless transmission of seed borne Botrytis cinerea into the seed of next generation Lettuce plant (Lactuca sativa). J. Plant. Sci. Res. 3:140.

Yazgan, A., Özcengiz, G., and Marahiel, M. A. (2001). Tn10 insertional mutations of Bacillus subtilis that block the biosynthesis of bacilysin. Biochim. Biophys. Acta. 1518, 87-94. doi: 10.1016/S0167-4781(01)00182-8

Yu, D., Wang, J., Shao, X., Xu, F., and Wang, H. (2015). Antifungal modes of action of tea tree oil and its two characteristic components against Botrytis cinerea. J. Appl. Microbiol. 119, 1253-1262. doi: 10.1111/jam.12939

Zhang, Q. X., Zhang, Y., Shan, H. H., Tong, Y. H., Chen, X. J., and Liu, F. Q. (2017). Isolation and identification of antifungal peptides from Bacillus amyloliquefaciens W10. Environ. Sci. Pollut. Res. Int. 24, 25000-25009. doi: 10.1007/s11356-017-0179-8

Zhang, X., Li, B., Wang, Y., Guo, Q., Lu, X., Li, S., et al. (2013). Lipopeptides, a novel protein, and volatile compounds contribute to the antifungal activity of the biocontrol agent Bacillus atrophaeus CAB-1. Appl. Microbiol. Biotechnol. 97, 9525-9534. doi: 10.1007/s00253-013-5198-x

Conflict of Interest Statement: LT is a full-time employee of Xtrem Biotech S.L., company that holds an exclusive licence agreement on the patent that protects XT1 industrial exploitation. MR, VB, and IS declare that the research was conducted in the absence of any commercial or financial relationships that could be construed as a potential conflict of interest.

Copyright (C) 2018 Toral, Rodríguez, Béjar and Sampedro. This is an open-access article distributed under the terms of the Creative Commons Attribution License (CC BY). The use, distribution or reproduction in other forums is permitted, provided the original author(s) and the copyright owner are credited and that the original publication in this journal is cited, in accordance with accepted academic practice. No use, distribution or reproduction is permitted which does not comply with these terms. 